\title{
Maximal covering location problem for nuclear medicine clinics allocation in Nigeria
}

\author{
Olalekan J. Taiwo ${ }^{1}$ [D $\cdot$ Akintunde T. Orunmuyi ${ }^{2}$
}

Received: 6 December 2020/Revised: 17 April 2021/Accepted: 26 April 2021/Published online: 2 May 2021

(C) Korean Spatial Information Society 2021

\begin{abstract}
Several studies demonstrate the usefulness of nuclear medicine procedures for public health problems in developing countries. Little is known about the location and accessibility of nuclear medicine facilities, thus making the assessment of their location and allocation an integral part in strengthening nuclear medicine services in these countries. This paper employed the Maximal Covering Location Problem to identify the optimum numbers of University Teaching and Research Hospitals (UTRHs) that can be upgraded to provide Nuclear Medicine (NM) services to the largest number of Local Government Areas (LGAs) within a $200 \mathrm{~km}$ threshold drive time in Nigeria. It also identified developmental priority for the optimum UTRHs. Our analysis shows that about $26 \%$ of the LGAs are within $200 \mathrm{~km}$ distance from the two existing NM facilities and if NM services are restricted to only the UTRHs, $84 \%$ coverage of the LGAs can be achieved within a $200 \mathrm{~km}$ drive time of 11 UTRHs in Nigeria. Compared with others, Aminu Kano Teaching Hospital, Kano, Kano State should be prioritized because it consistently has between 90 and 110 LGAs within its $200 \mathrm{~km}$ distance. Our study identified the optimal locations for nuclear medicine facilities and offers additional theoretical insights into strengthening nuclear medicine services in developing countries.
\end{abstract}

Olalekan J. Taiwo

Olalekantaiwo@gmail.com; oj.taiwo@mail.ui.edu.ng

Akintunde T. Orunmuyi

Akin2nde@gmail.com

1 Department of Geography, Faculty of the Social Sciences, University of Ibadan, Ibadan, Oyo State, Nigeria

2 Department of Radiation Oncology, College of Medicine, University of Ibadan, Ibadan, Oyo State, Nigeria
Keywords Nuclear Medicine Clinics (NMCs) - Maximal Covering Location Problem (MCLP) · University Teaching and Research Hospitals (UTRHs) · Cancer · Nigeria

\section{Introduction}

The incidence of cancer has continued to increase in most African countries. Developing countries account for about $52 \%$ of the incidence of cancer and $70 \%$ of its death $[1,2]$. Parts of the reasons adduced for the widespread cancer infection and mortality include limited human and natural resources to combat the disease, poverty, and inaccessibility to the limited number of diagnostic and testing facilities among others [3-6]. Nuclear medicine has emerged as an aspect of medicine with potency in testing, diagnosis and treatment of cancer-related ailments. Nuclear medicine has been defined as a medical specialty that applies artificial radionuclides in a non-sealed state for diagnosis, therapy, and biomedical research which often entails the administration of radiopharmaceuticals to patients for diagnostic and therapeutic purposes [7, 8]. Despite lots of apprehension by the general public about the safety of the procedures, it is nonetheless painless, free of side effects and is generally safe [9]. Nigeria with an estimated cancer incidence rate of about 100,000 new cases yearly has two public nuclear medicine clinics [2]. Breast cancer and prostate cancer are the two most common malignancies observed in oncology referrals among Nigerian [9].

Prevention, early detection, diagnosis, treatment and palliative care and psychosocial support received by patient can be greatly influenced by accessibility. Therefore, whatever measures are adopted to reduce the burden of cancer incidence needs to consider accessibility to early 
diagnosis [2]. Approved University Teaching and Research Hospitals (UTRHs) are among health facilities that can be equipped to provide nuclear medicine-related services. This is because the two existing ones are located in UTRHs. Recent studies have also suggested that cancer survival is enhanced when treatment is rendered at UTRHs [5]. However, not all UTRHs can be equipped to provide nuclear medicine-related services due to the high cost of equipment coupled with dwindling accessible financial resources aftermath of the COVID-19 pandemic and its consequences on crude oil earning in developing countries like Nigeria. Hence a method of identifying those UTRHs that will minimize the aggregate travel distance is required.

Five questions have always constituted a challenge in public service provisioning and these are (a) where should the facility be located (b) which population would the facility serve (c) how many of such facilities are required to ensure adequate coverage of the population (d) how can equity be guaranteed and (e) given the limited and dwindling resources, how should facility expansion be prioritized. The diverse interpretations of the goal of maximizing public welfare lead to some possible location-allocation models of which the Maximal Covering Location Problem (MCLP) is one. The MCLP, therefore, emerged because of the need to specify the maximum distance or time constraints in formulating a location problem since it has been found that the p-median solutions which minimize the weighted travel distance may be inequitable, forcing few people to travel far (Rahman and Smith, 2000). The method minimizes the total cost of transportation and maximizes the number of people served within the desired service distance by locating a fixed number of facilities. The MCLP is used to identify the minimum number of facilities necessary to achieve coverage within the maximum distance. The location of a potential new nuclear medicine facility lends itself well to the MCLP. There is strong epidemiologic evidence that widespread screening for breast cancer with mammography and clinical breast examination results in mortality reductions [10]. Physicians report that they make decisions to refer or not to refer women for routine screening based on barriers such as lack of transportation and f local availability [3].

Three preventive strategies for cancers have been identified by the [11] and the success of two out of the three depends largely on fairly good geographic access to a nuclear medicine facility. While the first preventive strategy focused on reducing exposure to cancer risk factors, the second focused on the early detection of cancer through screening and the third focused on the treatment or palliative care given to diagnose cancer patients [2, 12]. Early detection of cancer can be greatly influenced by access to a cancer diagnosis facility. It has been noted that patients with muscle invasive bladder cancer travelling farther for treatment were associated with a lower probability of overall mortality most especially those treated in UTRHs [6]. Although centralization of cancer treatment services has merit nevertheless, there is sufficient evidence to show a shorter survival for people with rectal cancer who live relatively far from radiotherapy facilities and hence the need to reduce the aggregate distance travels by cancer patients to enhance their survival [13]. Distance to health care facility most especially for specialized care may also influence the choice of method of treatment opted for. Women with early stage breast cancer who live far from a radiation therapy facility may be more likely to opt for mastectomy over breast conserving surgery [14].

The effects of facility type on treatment performed and the overall survival of cancer patients have been explored and while some have argued that there was no significant impact of facility size or hierarchy on either on treatment performed or overall survival, others have noticed that higher-volume facilities such as UTRHs had a lower risk of mortality compared with patients treated at lower-volume facilities $[5,15]$. Thus, while some have advocated that cancer treatment can be conducted even at the community level most especially when patients are not willing to travel over a fairly long distance, other groups have justified the use of UTRHs for treatment. Furthermore, travel distance/time has been established as a key barrier affecting access to cancer treatment services [13, 16]. Baade et al. [13] established a distance-decay relationship between distance from radiotherapy and the number of cancer patient's mortality. The necessity of long-distance travel may increase the inconvenience or cost of radiotherapy to a point where it simply is not feasible to receive treatment $[4,10]$. Barrier imposed by distance, therefore, remained a valid concern and may influence treatment options among cancer patients [14]. However, living in a county without a radiation-treatment facility was associated with a 50\% lower likelihood of receiving radiotherapy after BCS [17].

The two existing NMCs are serving an estimated population of 199,805,437 spreading over a landmass of 923,770 km (United Nations Department of Economic and Social Affairs: Population Division; National Bureau of Statistics, 2017). The NMCs are not distributed in response to either the population distribution or landmass. Consequently, a large number of patients in need of nuclear medicine service are disadvantaged by the distance to NMCs most especially women [10]. Although, the need to established NMCs equipped to provide investigations, radiotherapy, chemotherapy and radical surgery in the six geopolitical zones had been reported [2], however, the basis of their allocation among states in each of the geopolitical zones was not stipulated. The two prominent challenges confronting nuclear medicine utilization in Nigeria are the inadequate number of nuclear medicine 
facilities and the considerably long distance travel to access care [9]. Hence, the need for strategic planning and establishment of more NMCs to cater to regional needs as a way to mitigate the challenges. Different threshold distances have been used in assessing either accessibility or availability of health care facilities. As an example, [20] used 30 min drive time to a mammography facility as an indicator of accessibility. At present, Nigeria does not have any policy on the average distance that a patient should travel to utilize NMCs. This may have limited the expansion of the existing ones. There is a need to priorities the development and implementation of policies and measures that will reduce the burden faced by rural and remote patients with cancers [13]. This study, therefore, identified the maximum number of NMCs using the existing UTRHs that will guarantee that the maximum number of LGAs are served at the lowest possible distance [18]. The study represents the first attempt not only at understanding the MCLP of NMCs in Nigeria but also represents an attempt at identifying the number of NMCs required to ensure maximum coverage of the country.

\section{Materials and methods}

Data on the number of UTRHs in Nigeria was sourced from the Medical and dental council of Nigeria website [35]. In all, there are 24 UTRHs in Nigeria. The coordinates of the two existing NMCs and that of UTRHs were geocoded using ArcGIS 10.7 (Environmental Systems Research Institute, Inc.-ESRI, Redlands, California). The centroid of the 774 LGAs in Nigeria was designated as the demand nodes for the NMCs services while the supply node in the analysis is the existing nuclear medicine facilities at the University College Hospital (UCH), Ibadan, Oyo State and the one at the University of Abuja Teaching Hospitals, Gwagwalada, Abuja. The LGA represents one of the smaller administrative subunits for which data is available. It is an administrative level that is much closer to the grassroots for planning. The LGA scale was used as the level of analysis, given the necessity of conducting MCLP analysis at a highly disaggregated scale. Given the need to increase the number of existing NMCs in Nigeria, the upgrading of existing UTRHs was considered [5]. The UTRHs are most likely to have human resources that either has the knowledge and experience of nuclear medicine or can be readily trained to carry out a nuclear medicine-related assessment. The drive speed used in this analysis is $60 \mathrm{~km} / \mathrm{hr}$ due mostly to the poor road conditions especially the intracity routes $[19,20]$. This was used in estimating the time it will take to navigate through each road network that participates in the estimation of the coverage area of each facility. A travel constraint of

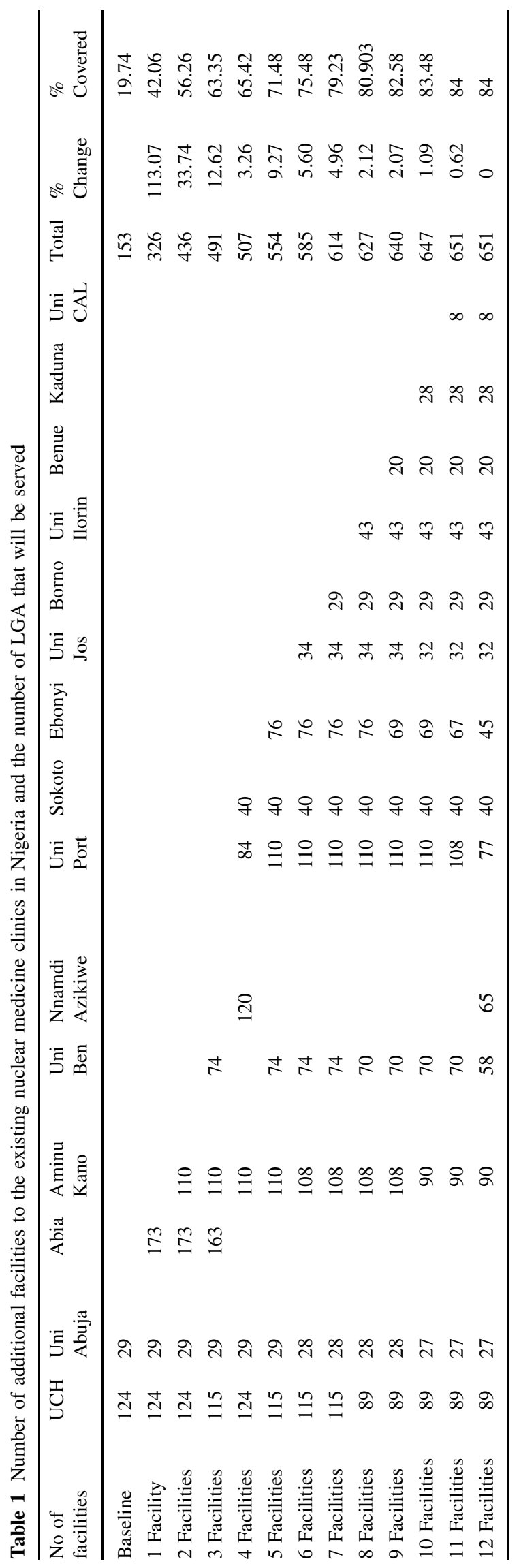




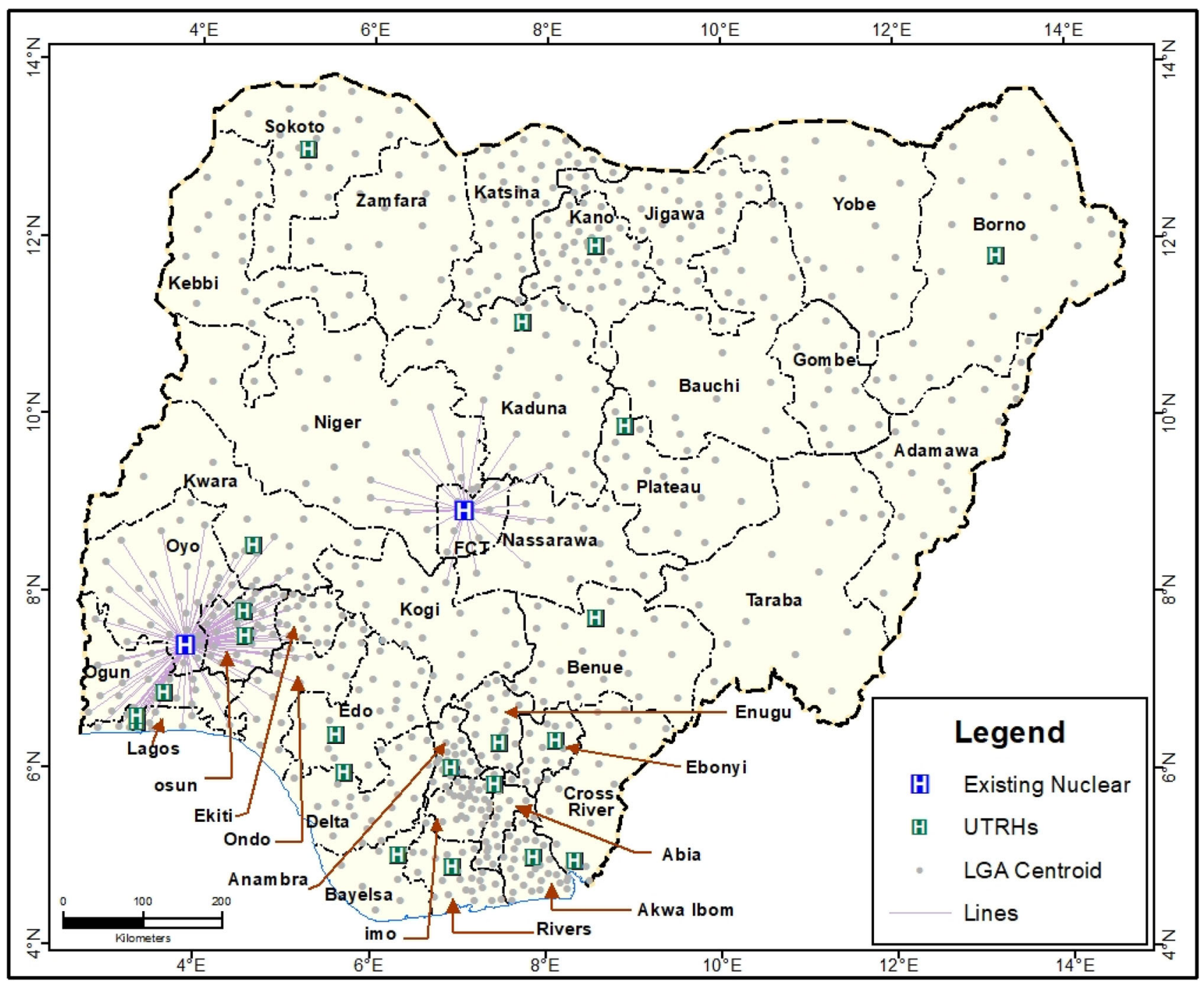

Fig. 1 Allocation of LGAs to the existing nuclear medicine clinics using $200 \mathrm{~km}$ drivetime

$200 \mathrm{~km}$ was applied to the weighted distance data calculation. Thus, if a node is more than $200 \mathrm{~km}$ from a facility, the demand represented by that node is not allocated to a facility. Without the travel limit, the model will assign all nodes by default to a facility [10]. The drive-time analysis was conducted to identify LGAs that are within the $200 \mathrm{~km}$ drive time from the nearest NMCs. A search is made for a stable condition in which destinations are assigned to their nearest source, and these sources are similarly placed at locations minimizing their distances from their respective demand points. Also, the maximum number of UTRHs that will optimally serve all the LGAs at the specified drive time were identified. The MCLP algorithm was implemented to estimate the number of LGAs at a different drive time with the incremental addition of the optimally selected UTRHs. The drive time of $60 \mathrm{~km} / \mathrm{hr}$ was used because it represents the average maximum drive speed on highways. It has been noted that a vehicle travelling above this speed limit is susceptible to accident [21, 22]. Since the distance is fixed at $200 \mathrm{~km}$, the number of LGAs to be served with increasing numbers of the identified optimal UTRHs were evaluated. This becomes imperative because there is no government threshold distance that patients must travel to access NMCs in Nigeria. The service area of these optimum UTRHs was subsequently overlaid on the administrative map of Nigeria to estimate the percentage area of each state within the specified drive time. The irregular shape of the drive time areas was a function of the pattern of the existing road network and road characteristics. Drive-time distances for this study were calculated using the shortest travel routes and the drive time speed adopted was $60 \mathrm{~km} / \mathrm{h}$ because of the poor nature of roads in Nigeria. The percentage area of each state within the 30 min drive times was also estimated [18, 20]. 


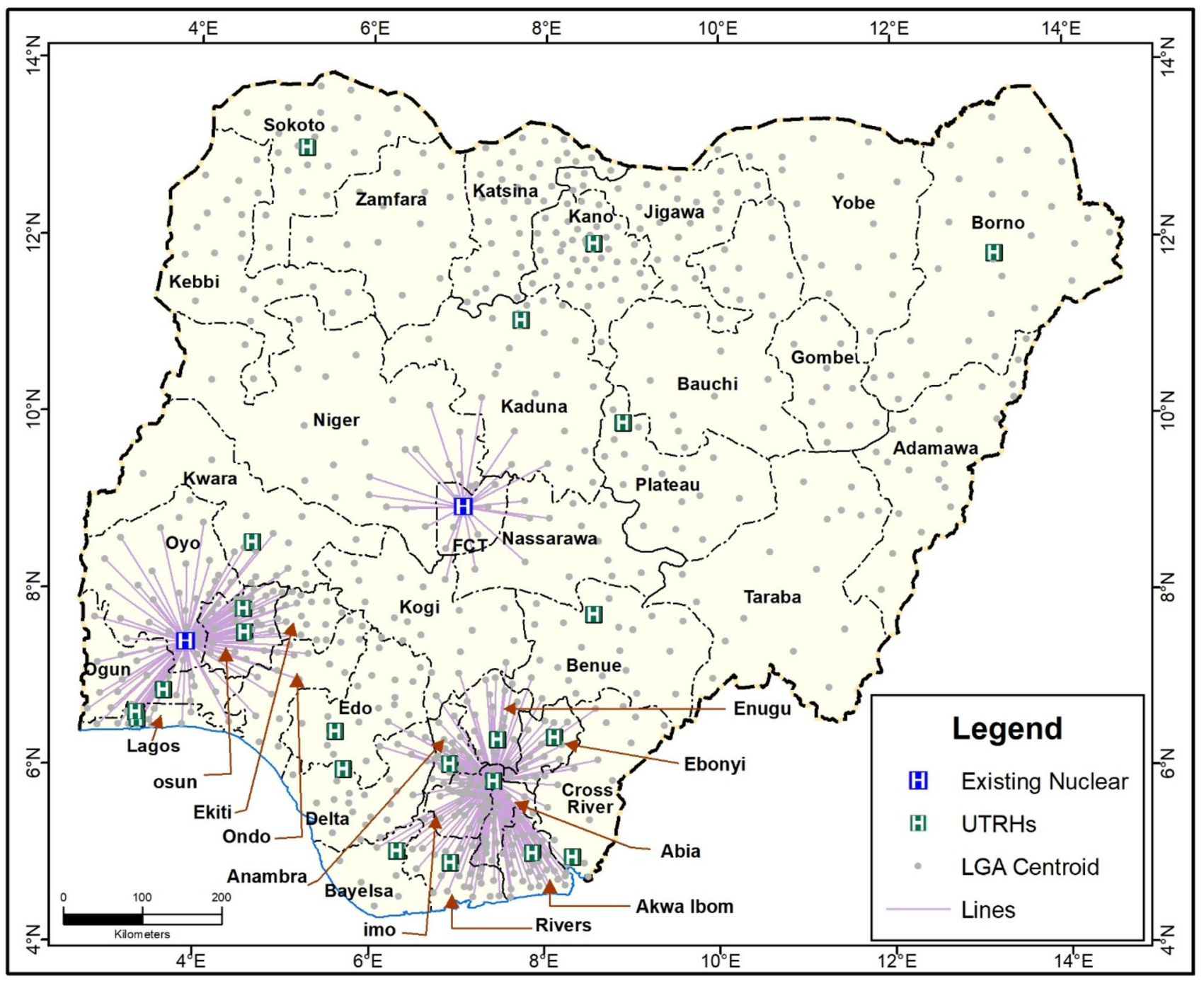

Fig. 2 The addition of Abia State University Teaching Hospital, Uturu to the existing NMCs

\section{Results}

\subsection{Identification of optimal UTRHs coverage for LGAs in Nigeria}

Only $5.2 \%$ of the States in Nigeria have NMCs and there are 204 LGAs within the $200 \mathrm{~km}$ drive time from the two existing NMCs in Nigeria. The University College Hospital (UCH), Ibadan has 160 LGAs within $200 \mathrm{~km}$ while the University of Abuja Teaching Hospital has 44 LGAs within its $200 \mathrm{~km}$ drive time (Table 1 and Fig. 1). About $26 \%$ of the LGAs in Nigeria are within the $200 \mathrm{~km}$ drive time to the existing NMCs, while the remaining $74.0 \%$ are more than $200 \mathrm{~km}$ from at least one of the existing NMCs. In Southwestern Nigeria, $90.51 \%$ of the LGAs are within the drive time of $200 \mathrm{~km}$ from the NMC at the University College Hospital (UCH) Ibadan. The NMC at the University of Abuja is within a $200 \mathrm{~km}$ drive time from 29 LGAs in FCT, Niger, Kaduna, Nassarawa and Kogi States (Fig. 1).

The Abia State University Teaching Hospital, Uturu, Abia State was the first optimal UTRHs identified and there are 173 (22.35\%) LGAs within the $200 \mathrm{~km}$ drivetime from this newly added UTRH (Fig. 2, Table 1). This new addition to the existing NMCs will reduce the distance travelled by people in the southeast and south-south geopolitical zones in the country. The number of LGAs that will be within the $200 \mathrm{~km}$ drive time of this facility will be more than the combined number of LGAs within the $200 \mathrm{~km}$ drive time of the two existing NMCs. Furthermore, the addition of this new NMC will increase the aggregate number of LGAs within the $200 \mathrm{~km}$ drive time to MNCs from 19.74 to $42.06 \%$, while there will be a $113.07 \%$ increase in the number of LGAs within the $200 \mathrm{~km}$ drive time to the nearest NMC. The choice of the Abia State University Teaching Hospital, Uturu could have 


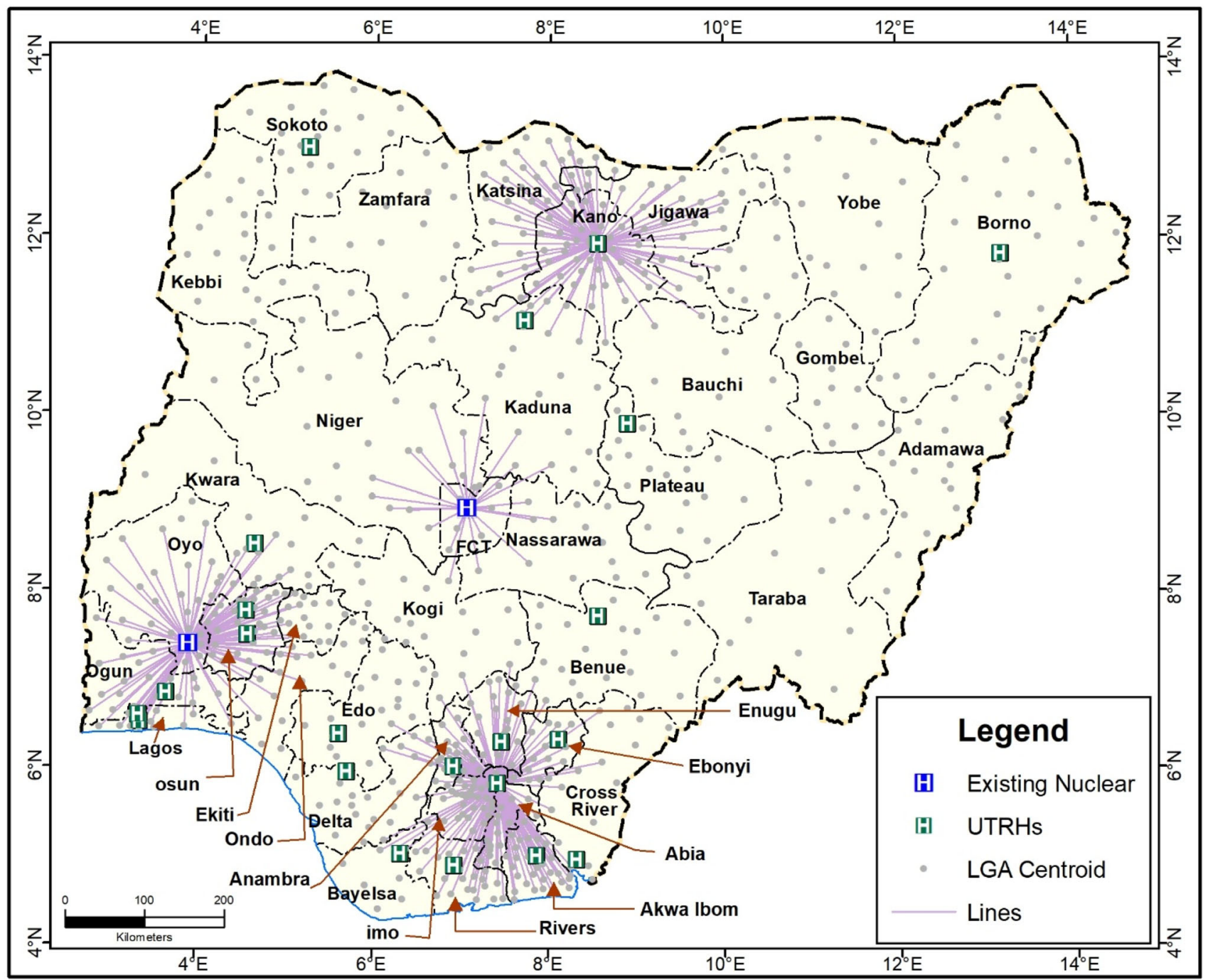

Fig. 3 The addition of the Aminu Kano Teaching Hospital, Kano

been due to the high cluster of LGAs in the southeast and south-south geopolitical zone of the country.

The Abia State University Teaching Hospital, Uturu and the Aminu Kano Teaching Hospital, Kano are the two most optimal UTRHs. The addition of these two UTRHs to the existing NMCs will ensure that $436(56.26 \%)$ of the LGAs in Nigeria are within the $200 \mathrm{~km}$ drive time distance from the nearest NMCs. This will represent a $33.74 \%$ increase from just one additional facility (Abia State University Teaching Hospital, Uturu). These two UTRHs will be within $200 \mathrm{~km}$ distance from 283 LGAs (Table 1, Fig. 3). The addition of the second optimal UTRH (Aminu Kano Teaching Hospital, Kano) ensured that most of the LGAs in Kano, Katsina and Jigawa States are within the $200 \mathrm{~km}$ drive time. However, much of Sokoto, Kebbi and Zamafara, Yobe, Borno, Gombe, Adamawa, Taraba, Benue and Plateaus states are not covered (Fig. 3).
The addition of these three optimal UTRHs (The Abia State University Teaching Hospital, Uturu, the Aminu Kano Teaching Hospital, Kano and University of Benin Teaching Hospital, Benin City) to the two existing NMCs will increase the number of LGAs within $200 \mathrm{~km}$ to 491 $(63.35 \%)$ while there will be a $12.62 \%$ increase in the number of LGAs within the $200 \mathrm{~km}$ from at least one NMC (Table 1). The addition of the third most optimal UTRH (University of Benin Teaching Hospital) will ensure that most LGAs in Oyo, Ogun, Osun, Ekiti, Ondo, Edo, Delta, Ebonyi, Anambra, Enugu, Abia and Rivers States are within the $200 \mathrm{~km}$ drivetime from at least one NMC. However, much of the northeastern, northwestern and northcentral geopolitical zones remained largely uncovered (Fig. 4).

The four most optimal UTRHs that will optimize the maximum number of LGAs within a $200 \mathrm{~km}$ distance are the Aminu Kano Teaching Hospital, Kano, Nnamdi 


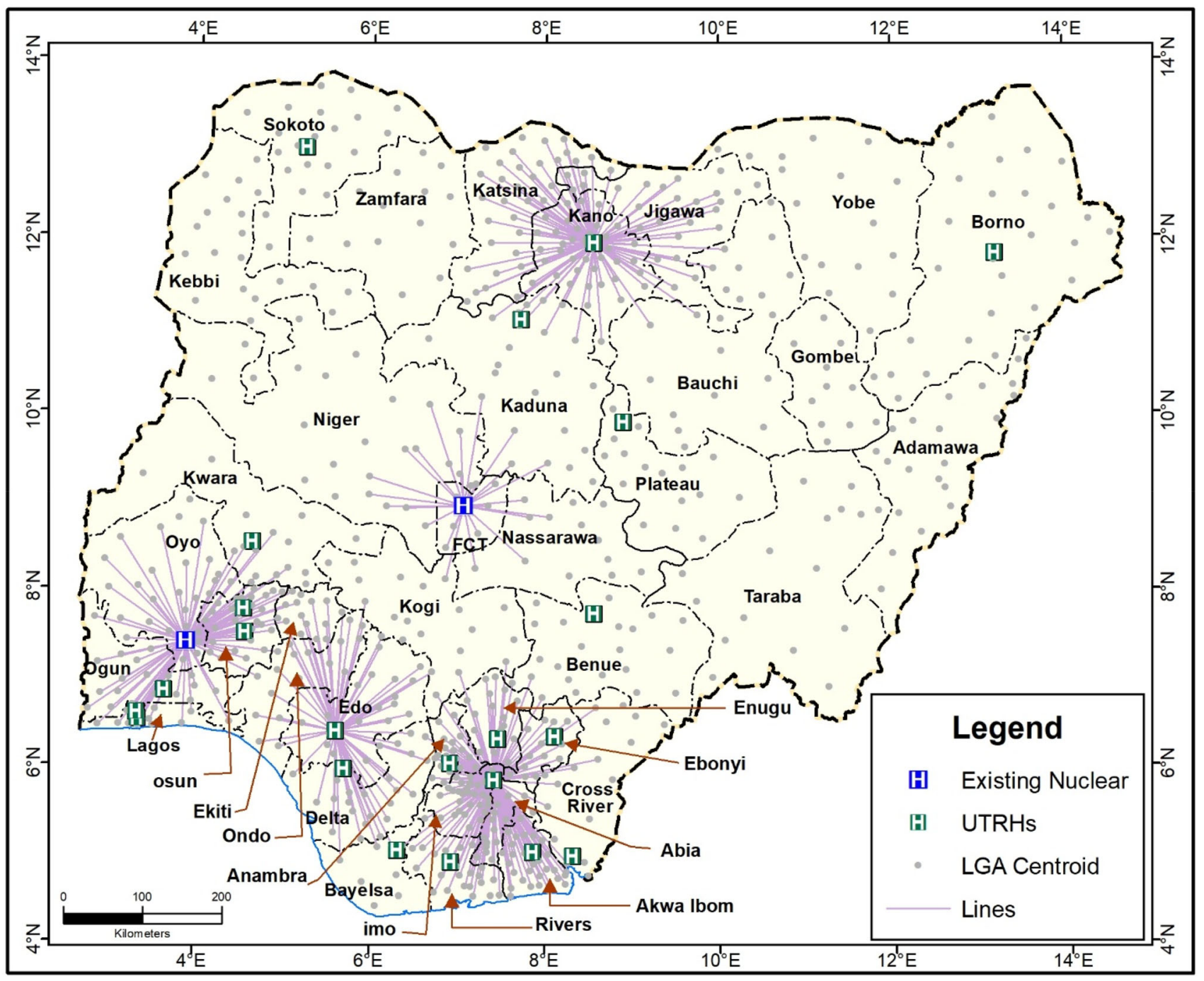

Fig. 4 The addition of University of Benin Teaching Hospital, Benin City

Azikiwe University Teaching Hospital Nnewi, University of Port-Harcourt Teaching Hospital, River State and the Usmanu Danfodiyo University Teaching Hospital, Sokoto. These four UTRHs will increase the number of LGAs within the $200 \mathrm{~km}$ drive time from 491 to 507 (3.26\% increase) while the percentage of LGAs within the $200 \mathrm{~km}$ drive time will increase to $65.42 \%$ (Table 1). The Abia State University Teaching Hospital, Uturu, and University of Benin Teaching Hospital, Benin City that were part of the three most optimal UTRHs were not included in the four optimal UTRHs. The inclusion of the University of Port Harcourt Teaching Hospital will ensure that most of the LGAs in the south-south geopolitical zone are within the $200 \mathrm{~km}$ corridor while the exclusion of the University of Benin Teaching Hospitals will leave most of the LGAs in Edo and Ondo states outside of the $200 \mathrm{~km}$ drive time (Fig. 5). Thus, the identification of the most optimal facilities is not cumulative and largely depend on the number of facilities consider as well as the spatial configuration of the demand points. Out of these four new UTRHs, the Aminu Kano Teaching Hospital, Kano and Nnamdi Azikiwe University Teaching Hospital Nnewi have the largest number of LGAs (230) within the $200 \mathrm{~km}$ drive time. The addition of the fourth facility at the Usmanu Danfodiyo University Teaching Hospital, Sokoto, Sokoto State will enable 40 of the LGAs in the northwest geopolitical zones to be within the $200 \mathrm{~km}$ drive time from this NMC. This facility will serve all the LGAs in Sokoto State and some in Kebbi and Zamfara States.

The five UTRHs that will optimize the number of LGAs within the $200 \mathrm{~km}$ drive time from NMCs are the Aminu Kano Teaching Hospital, Kano, University of Benin Teaching Hospital, Benin City, University of Port-Harcourt Teaching Hospital, River State, the Usmanu Danfodiyo University Teaching Hospital, Sokoto and the Ebonyi State University Teaching Hospital, Abakaliki. These five 


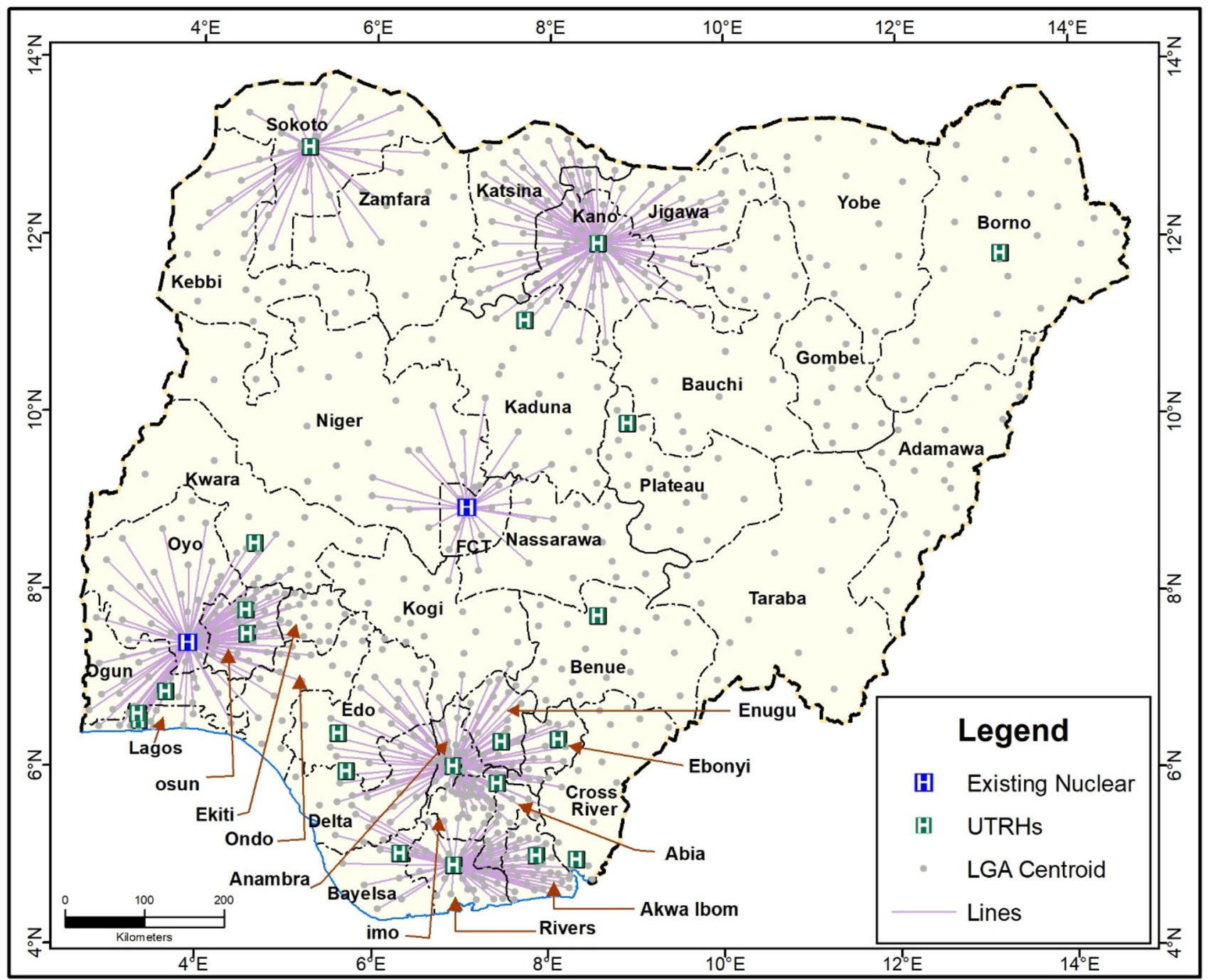

Fig. 5 The addition of the Usmanu Danfodiyo University Teaching Hospital, Sokoto State

UTRHs will increase the number of LGAs within the $200 \mathrm{~km}$ drive time to $554(71.48 \%$ ) which is about a $9.27 \%$ increase from when four optimal UTRHs were considered. The Aminu Kano Teaching Hospital, Kano (110), and University of Port-Harcourt Teaching Hospital, River State (110) were the UTRHs with the highest number of LGAs within the $200 \mathrm{~km}$ drive time (Table 1). Furthermore, the Nnamdi Azikiwe University Teaching Hospital Nnewi which had the largest number of LGAs within its $200 \mathrm{~km}$ drive time using four optimal UTRHs was not part of the optimal UTRHs when five optimal UTRHs were considered. This implies that optimal UTRHs selection is not progressively incremental. The addition of the fifth UTRH (Ebonyi State University Teaching Hospital) will ensure that most of the LGAs in Ebonyi, Anambra, Cross Rivers, and some LGAs in Benue and Kogi States are within the $200 \mathrm{~km}$ drive time (Fig. 6). Most of the LGAs in the northeastern geopolitical zones are still largely outside of the $200 \mathrm{~km}$ drive time to the nearest NMCs.

The addition of the Jos University Teaching Hospital to the existing five optimal facilities will ensure that most LGAs in Plateau state and some LGAs in Kaduna, Bauchi, and Nassarawa States are within the $200 \mathrm{~km}$ drive time from at least one NMC. Although, most parts of Niger State, and also, the States in the northeastern geopolitical zones are still without NMC. The six optimal UTRHs are the Aminu Kano Teaching Hospital, Kano, University of Benin Teaching Hospital, Benin City, University of PortHarcourt Teaching Hospital, River State, the Usmanu Danfodiyo University Teaching Hospital, Sokoto, the Ebonyi State University Teaching Hospital, Abakaliki and Jos University Teaching Hospital, Jos. These six facilities increased the number of LGAs within the $200 \mathrm{~km}$ drive time to $585(75.48 \%)$ and this represents a $5.60 \%$ increase (Table 1). The University of Port-Harcourt Teaching 


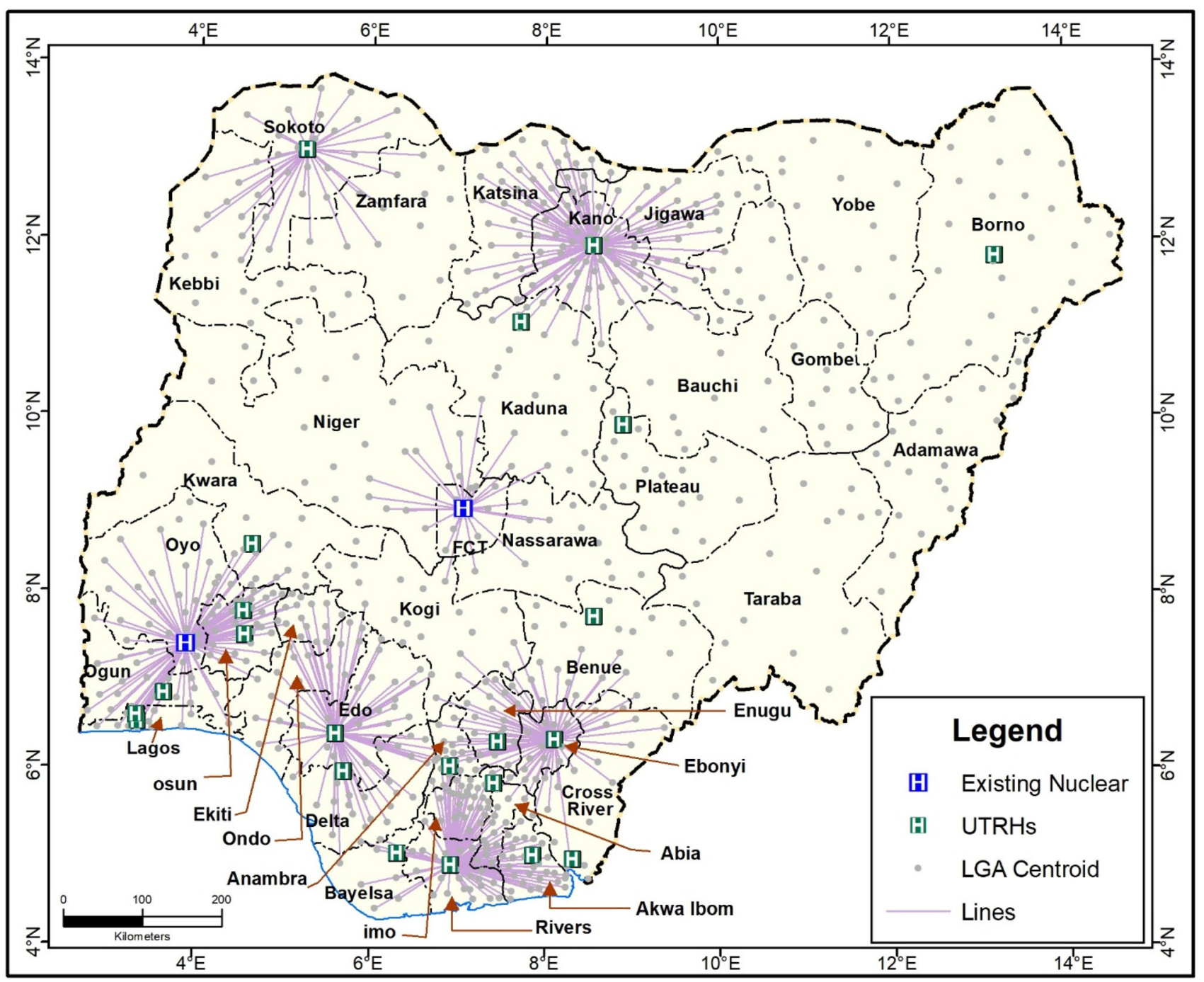

Fig. 6 The addition of the Ebonyi State University Teaching Hospital, Abakaliki

Hospital, River State (110) and the Aminu Kano Teaching Hospital, Kano (108) have the highest number of LGAs within the $200 \mathrm{~km}$ drive time from the nearest NMCs (Fig. 7).

The seven most optimal UTRHs that can provide nuclear medicine service to the largest number of LGAS in Nigeria are the Aminu Kano Teaching Hospital, Kano, University of Benin Teaching Hospital, Benin City, University of Port-Harcourt Teaching Hospital, River State, the Usmanu Danfodiyo University Teaching Hospital, Sokoto, the Ebonyi State University Teaching Hospital, Abakaliki, Jos University Teaching Hospital, Jos and the University of Maiduguri Teaching Hospital, Maiduguri Borno State. A total of 614 (79.22\%) LGAs will be with a $200 \mathrm{~km}$ drive time from at least one UTRHs providing nuclear medicine services (Table 1). The University of Port-Harcourt Teaching Hospital, River State (110) and the Aminu Kano Teaching Hospital, Kano (108) will still have the largest number of LGAs within the $200 \mathrm{~km}$ drive time from at least one NMCs. The addition of the seventh optimal facility at the University of Maiduguri Teaching Hospital, Maiduguri Borno State to the existing facilities will ensure that 29 additional LGAs are within the $200 \mathrm{~km}$ distance from NMC. The 29 LGAs include some from parts of Yobe and Adamawa states. With the seven facilities, none of the LGAs in Gombe and Taraba states is within the $200 \mathrm{~km}$ drive time from NMCs (Fig. 8).

The eight optimal UTRHs that should be designated as NMCs include the Aminu Kano Teaching Hospital, Kano, University of Benin Teaching Hospital, Benin City, University of Port-Harcourt Teaching Hospital, River State, the Usmanu Danfodiyo University Teaching Hospital, Sokoto, the Ebonyi State University Teaching Hospital, Abakaliki, Jos University Teaching Hospital, Jos, the University of Maiduguri Teaching Hospital, Maiduguri Borno State and the University of Ilorin Teaching Hospital, 


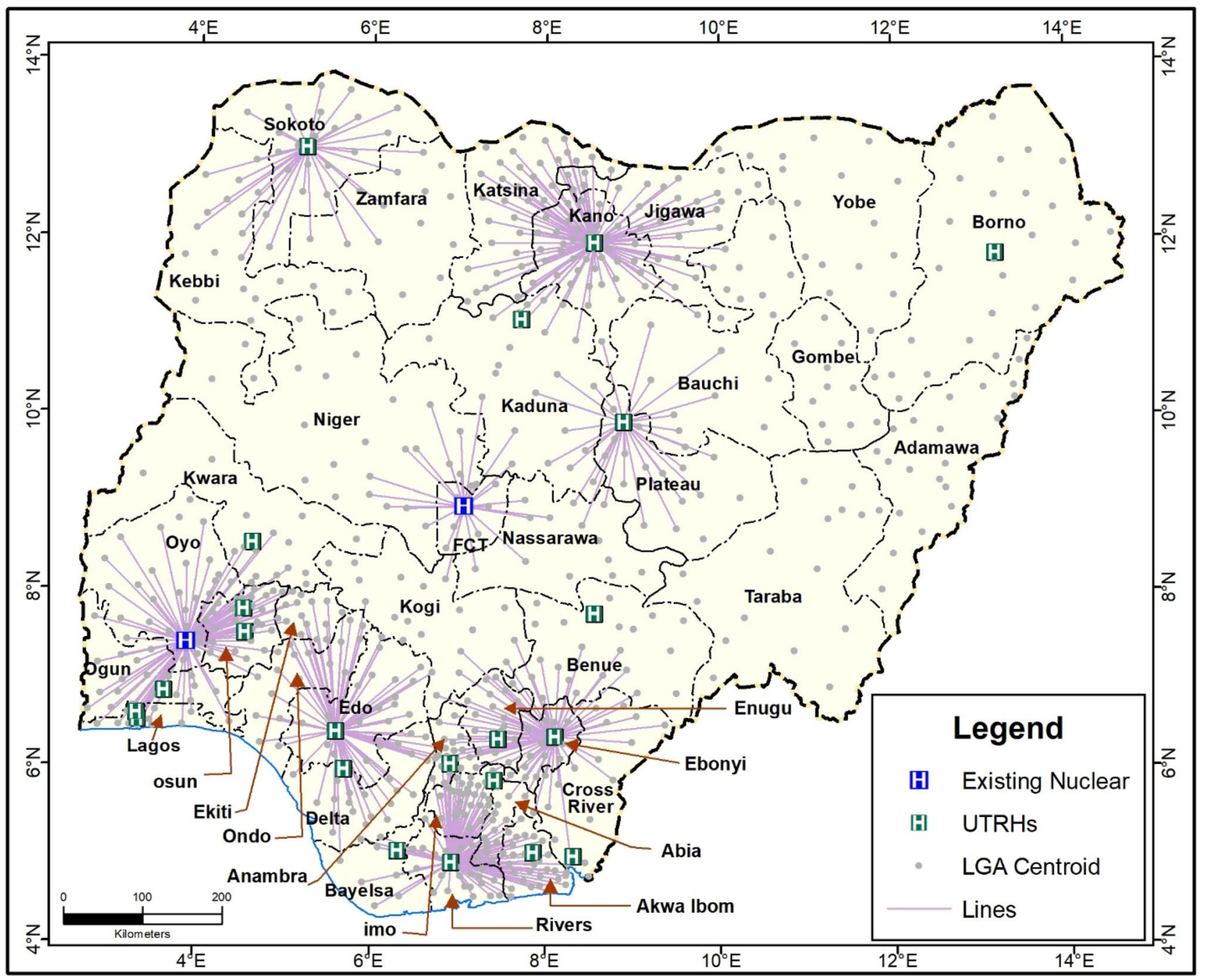

Fig. 7 The addition of the Jos University Teaching Hospital, Jos, Plateau State

Ilorin, Kwara State (Table 1). The inclusion of the University of Ilorin Teaching Hospital, Ilorin, Kwara State reduced the percentage of LGAs previously within the $200 \mathrm{~km}$ drive time from the University College Hospital, Ibadan by $22.61 \%$, although it provides sufficient coverage for most of the LGAs in Kwara State, and some parts of Oyo, Osun, Ekiti, Kogi and Niger States (Fig. 9). In all, $627(80.90 \%)$ of the LGAs will be within $200 \mathrm{~km}$ drive time from at least one NMC in Nigeria once the identified UTRHs are equipped. There is, however, a marginal increase in the number of LGAs $(2.12 \%)$ within the $200 \mathrm{~km}$ from what it was with seven UTRHs.

Similarly, the addition of the Benue State University Teaching Hospital Makurdi, Benue State to the existing eight optimal facilities previously identified increased the number of LGAs within the $200 \mathrm{~km}$ distance to 640 $(82.58 \%)$ and this will increase the percentage of LGAs previously within the $200 \mathrm{~km}$ by $2.07 \%$ (Table 1 ). The inclusion of these UTRHs will ensure that nearly all the LGAs in Ebonyi State and some LGAs in Kogi State are within the $200 \mathrm{~km}$ drive time from this NMC (Fig. 10). The addition of the Benue State University Teaching Hospital, Makurdi, Benue State to the existing eight optimal facilities will only slightly reduce the number of LGAs within the $200 \mathrm{~km}$ drive time from the Ebonyi State University Teaching Hospital, Abakaliki. Despite the inclusion of this UTRH, LGAs in Gombe, Adamawa and Taraba States are still not within the $200 \mathrm{~km}$ drive time distance from any of the NMCs (Fig. 10).

The addition of the Ahmadu Bello University Teaching Hospital, Zaria, Kaduna State to the existing nine optimal facilities will increase the number of LGAs previously within $200 \mathrm{~km}$ drive time by $1.09 \%$ from 640 to 647 LGAs and thus, $83.48 \%$ of all the LGAs will be within $200 \mathrm{~km}$ drive time from at least one NMC (Table 1). The inclusion of the Ahmadu Bello University Teaching Hospital, Zaria, 


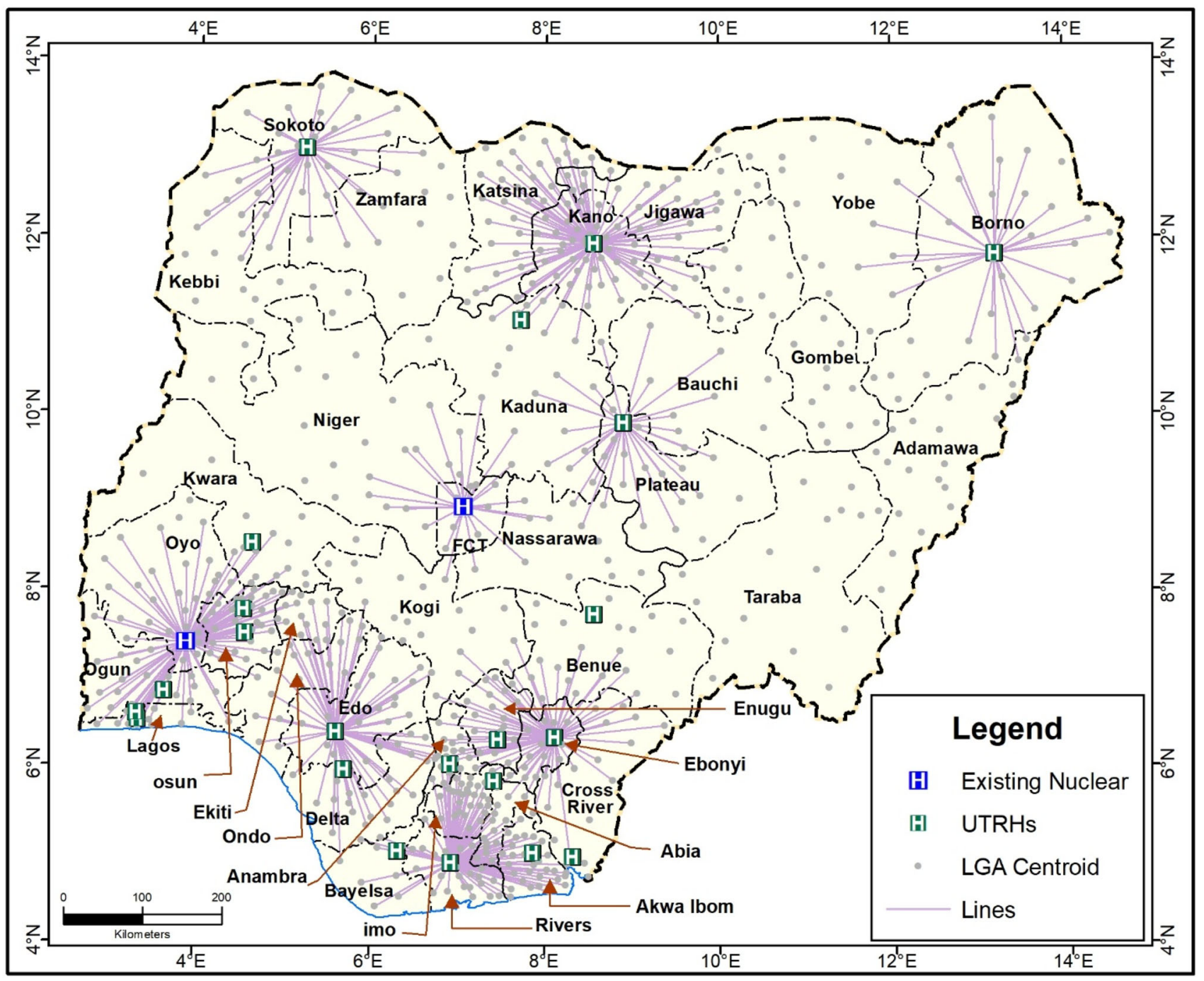

Fig. 8 The addition of the University of Maiduguri Teaching Hospital, Borno State

Kaduna State among the most optimal facilities will lead to a reduction in the number of LGAs within the $200 \mathrm{~km}$ drive time from the University of Abuja Teaching Hospital Gwagwalada, the Aminu Kano Teaching Hospital, Kano, and the Jos University Teaching Hospital. The UTRH nevertheless will be within a $200 \mathrm{~km}$ drive time distance from some of the LGAs in Kaduna and Zamfara States (Fig. 11).

The inclusion of the University of Calabar Teaching Hospital among the optimal UTRHs will ensure that 647 $(84.0 \%)$ LGAs are within the $200 \mathrm{~km}$ drive time from at least one NMC. This will increase the number of LGAs previously within the $200 \mathrm{~km}$ drive time by $0.62 \%$. It will ensure that most of the LGAs in the southeastern geopolitical zones are within the $200 \mathrm{~km}$ drive time from a least one NMC (Fig. 12).

After the eleventh optimal facility was reached, there was no increase in the number of LGAs within the $200 \mathrm{~km}$ drive time from NMCs. Thus, only $84.0 \%$ of the LGAs can be covered while the remaining $16.0 \%$ are outside the $200 \mathrm{~km}$ drive time from the nearest UTRH which are potential sites for the establishment of the NMCs. It should also be noted that before the identification of the fifth most optimal facilities, there was no consistent increase in the addition of optimal facility, however, after the fifth facility was identified, the addition becomes consistently incremental (Table 1). Also, the percentage contribution of the successive facilities was not as high as when it was not consistently incremental.

\subsection{Developmental priority}

In addition to the existing NMCs at the University College Hospital, Ibadan, Oyo state and the University of Abuja Teaching Hospital, Gwagwalada, the eleven identified optimal UTRHs which can be upgraded as NMCs are 


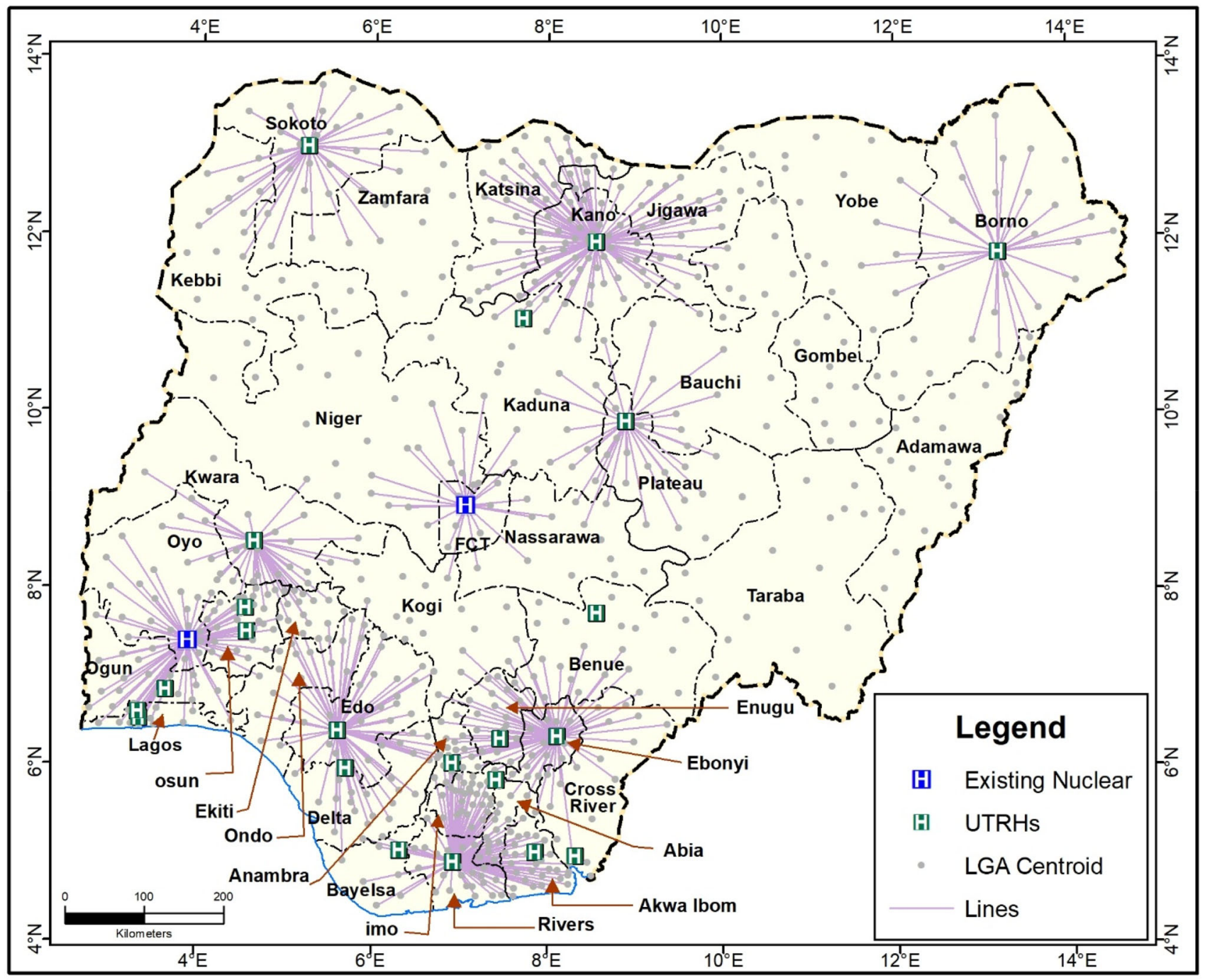

Fig. 9 The addition of the University of Ilorin Teaching Hospital, Ilorin, Kwara State

contained in Table 2. Among these new optimal UTRHs to be added, the Aminu Kano Teaching Hospital, Kano, Kano State and the University of Port-Harcourt Teaching Hospital, River State have the largest number of LGAs within their $200 \mathrm{~km}$ drive time and hence their capacity should be increased to accommodate the likely large number of patients.

Using the number of times each of the UTRHs featured in the optimal location analysis, the Aminu Kano Teaching Hospital, Kano, Kano State featured virtually in all, irrespective of the proposed number of facilities to be upgraded except when it was only one facility to be upgraded. Among the optimal UTRHs, the Nnamdi Azikwe University Teaching Hospital and the University of Calabar Teaching Hospital, Calabar, Cross River State featured only once (Table 1). The University of Benin Teaching Hospital, Benin City, the University of Port-Harcourt Teaching Hospital, River State and the Usmanu Danfodiyo
University Teaching Hospital, Sokoto featured eight times (Table 2). Therefore, the number of times each UTRHs featured in the optimality analysis could be used to prioritize their upgrade.

\section{Discussion}

Recent advances in imaging technology and radiopharmaceutical development point to a boom in nuclear medicine applications for diagnosis and treatment globally [23, 24]. NM is vital to the detection and treatment of cancers, yet most sub-Saharan African countries face challenges with the provision of NM services [25]. Outside South Africa, NM is not readily available in sub-Saharan African countries [26]. The current availability of NM in sub-Sahara Africa has been the result of decades of coordination between the International Atomic Energy Agency (IAEA) 


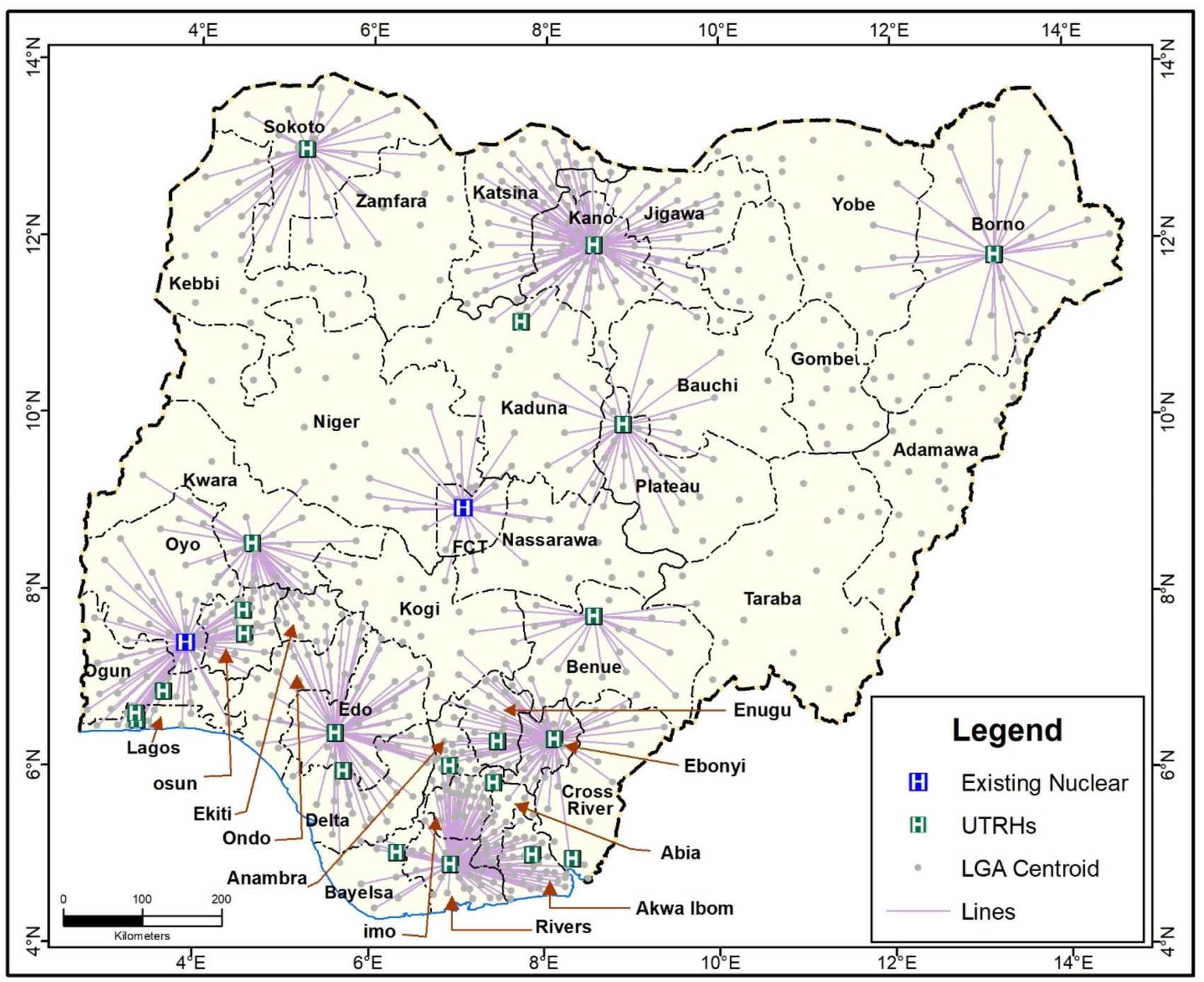

Fig. 10 The addition of the Benue State University Teaching Hospital Makurdi, Benue State

and individual African governments and marks the proof of concept that NM is feasible, even profitable, in African developing countries. Long term educational activities by the IAEA continues to prepare Africa for the expansion of NM and radiopharmacy facilities [27].

Our empirical assumption of a maximum travel distance of $200 \mathrm{~km}$ is well balanced with the limited resources and poor road infrastructure in Nigeria. Different threshold distances have been used in assessing either accessibility or availability of health care facilities [18]. The need to prioritize the development and implementation of policies and measures that will reduce the burden faced by rural and remote patients with cancers has been noted [13]. Nichols et al. [20] used $30 \mathrm{~min}$ drive time to a mammography facility as an indicator of accessibility. However, this drive time was derived for a developed country. More than half $(54 \%)$ of Nigerians live in rural settings and it is believed that up to $70 \%$ of Nigerians are extremely poor [28]. Less developed countries have less ideal road conditions that are associated with longer travel times. Furthermore, $200 \mathrm{~km}$ allows for maximum coverage to optimally serve most of the LGAs at the specified drive time, although shorter distances could be experimented with the increasing availability of resources.

The Aminu Kano Teaching Hospital (AKTH), Ebonyi State University Teaching Hospital (ESUTH) and Jos University Teaching Hospital (JUTH) ranked higher than the proposed centres in the national plan. As part of health strategic plans, most developed countries determine their nuclear medicine-specific targets following a needs assessment. Developing countries on the other hand often require financial and technical assistance to establish NM facilities and sustain their operations [24, 25, 29]. While AKTH and JUTH are federally funded hospitals, it is likely that their proximity to Abuja and the need for geopolitical balance may have discouraged their inclusion in the 


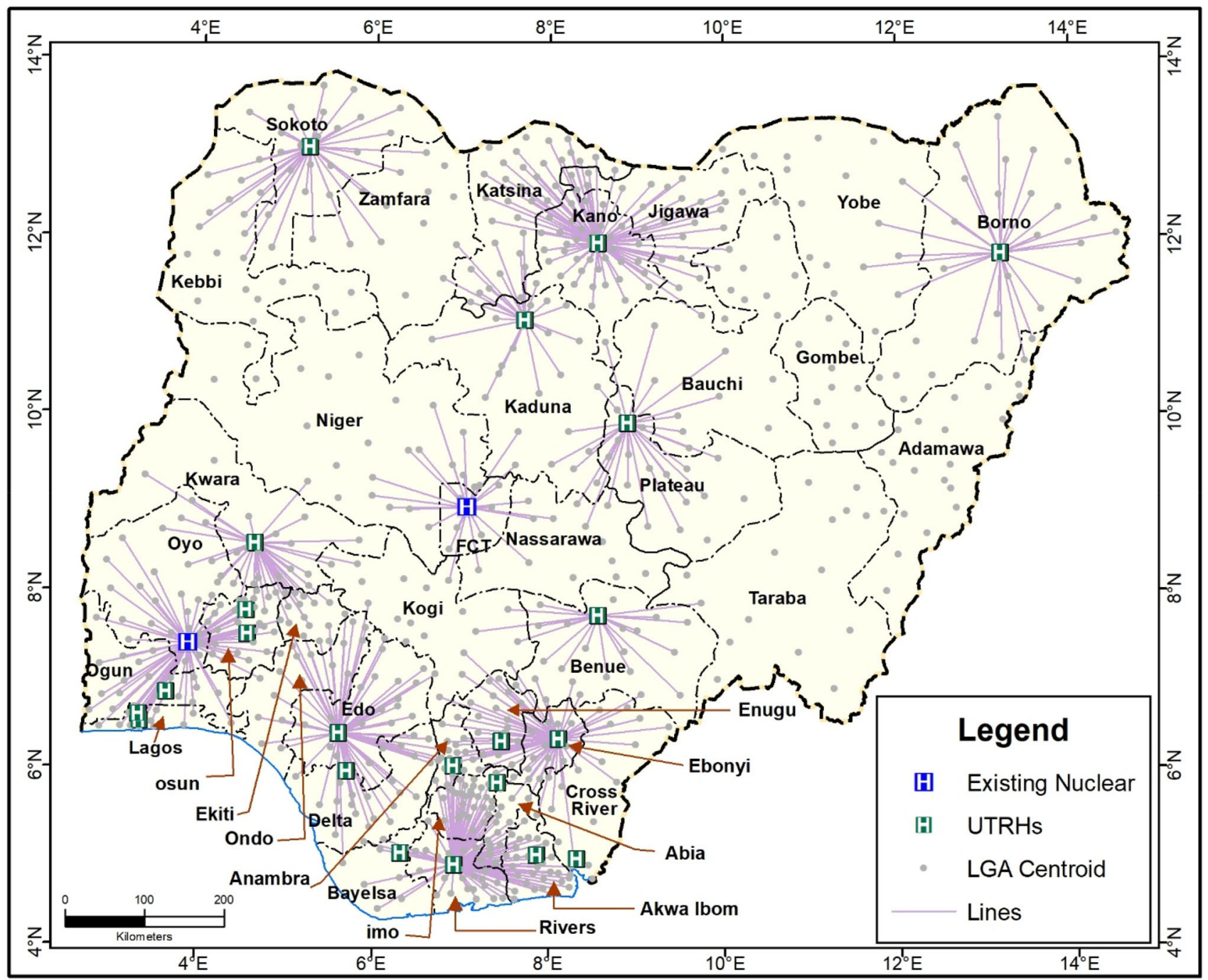

Fig. 11 The addition of the Ahmadu Bello University Teaching Hospital, Zaria, Kaduna State

National project. ESUTH, being a state funded institution, is ineligible. This confirms that formal methods for determining optimal locations have rarely been used as an aid to decision making for research and planning of health facilities in most developing countries [30].

Based on the analysis, only $84 \%$ coverage will be achieved if NMCs were only sited in UTRHs. Although, there is no consensus on the country specific thresholds for nuclear medicine facilities or resources [31]. Numerous methods in the literature could serve as a guide to appropriately locate specialized health services [32,33]. By their nature, specialized health services are limited in number and located in major town or cities. They tend to have low rates of referral due to barriers that limit their utilization including cultural and linguistic differences and other factors that disproportionately affect patients from other regions. Location analysis based on the total travel distance (or time) is a popular approach to public health facility planning in developing countries. Generally, the literature reports both positive and negative relationships between access to healthcare and public health outcomes [24, 32-34]. With just two NM centres in Nigeria, patients need to travel considerable distances to obtain services [9]. Further studies are required to ascertain the impact of travel distance on NM utilization rates in Nigeria. Basic NM facilities that provide less specialized service may be considered to expand the geographical coverage but must be built on feasibility studies to justify the expenditure.

\section{Conclusion}

Nuclear Medicine Clinics (NMCs) are becoming an increasingly important component of medical services globally. Utilization of the nuclear medicine services may have been greatly hampered by inaccessibility to NMCs 


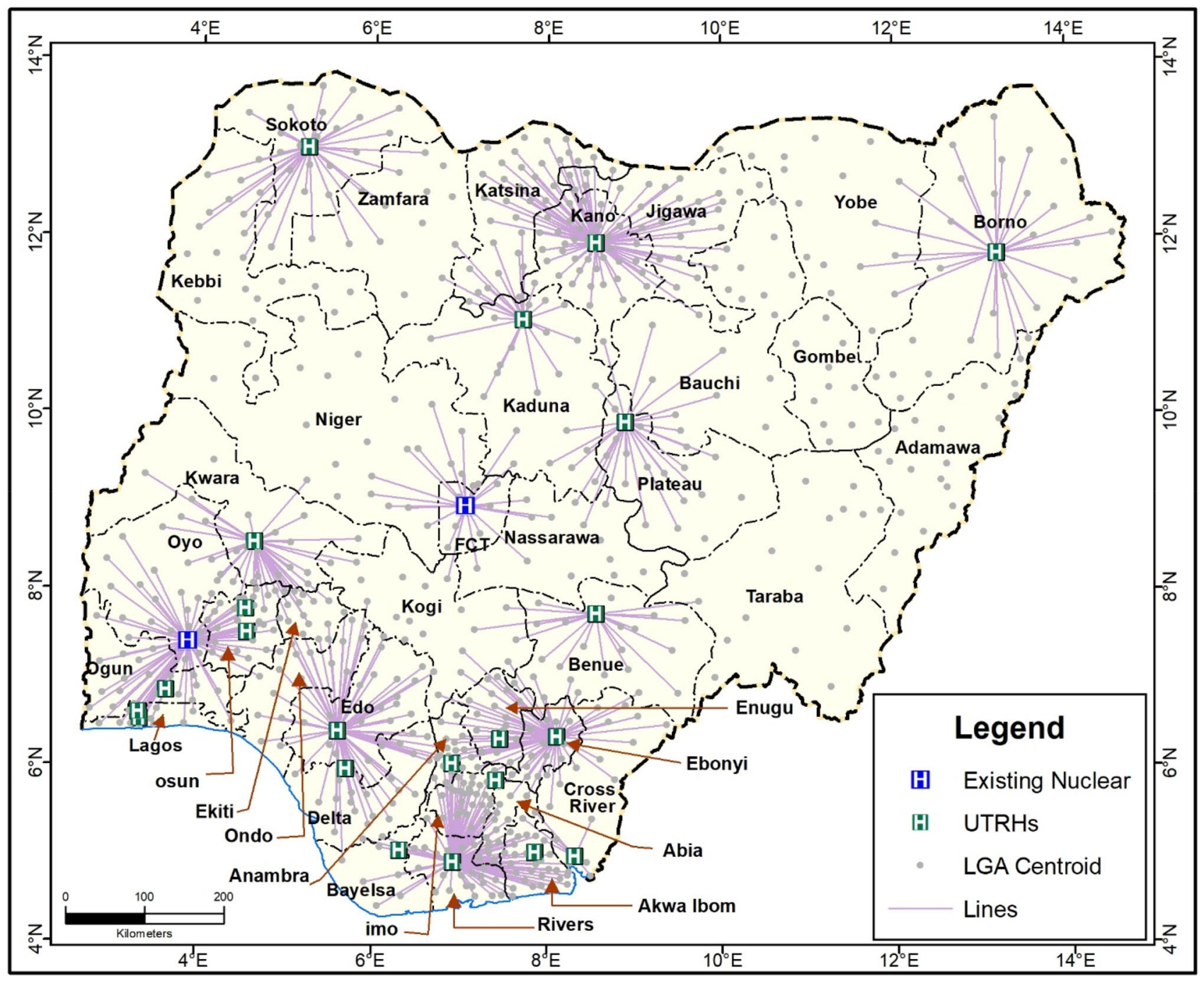

Fig. 12 The addition of the University of Calabar Teaching Hospital

Table 2 Ranking UTRHs for equipping based on the number of times a facility is optimal

\begin{tabular}{llrl}
\hline S/N & Name of facility & Frequency & Rank \\
\hline 1 & University College Hospital, Ibadan & 12 & Fixed \\
2 & University of Abuja Teaching Hospital Gwagwalada & 12 & Fixed \\
3 & Abia State University Teaching Hospital, Aba & 2 & 8 \\
4 & Aminu Kano Teaching Hospital, Kano, Kano State & 10 & 1 \\
5 & University of Benin Teaching Hospital, Benin City & 8 & 2 \\
6 & Nnamdi Azikiwe University Teaching Hosp. Nnewi & 1 & 9 \\
7 & University of Port Harcourt Teaching Hospital & 8 & 2 \\
8 & Usmanu Danfodiyo University Teaching Hospital, Sokoto, & 8 & 2 \\
9 & Ebonyi State University Teaching Hospital, Abakaliki & 7 & 3 \\
10 & Jos University Teaching Hospital, Jos, Plateau State & 6 & 4 \\
11 & University of Maiduguri Teaching Hospital, Maiduguri Borno State & 5 & 5 \\
12 & University of Ilorin Teaching Hospital, Ilorin, Kwara State & 4 & 6 \\
13 & Benue State University Teaching Hospital Makurdi, Benue State & 3 & 7 \\
14 & Ahmadu Bello University Teaching Hospital, Zaria, Kaduna State & 2 & 8 \\
15 & University of Calabar Teaching Hospital, Calabar, Cross River State & 1 & 9 \\
\hline
\end{tabular}


and the dwindling resources to increase the number of such facilities in the Low and Medium Income Countries (LMICs) like Nigeria. This study determined the numbers of LGAs that are within the $200 \mathrm{~km}$ distance of the two existing Nuclear Medicine Clinics (NMCs) in Nigeria. Only $26 \%$ of the LGAs in Nigeria are within the stipulated travel distance, hence the need to identify locations where additional NMCs can be located to ensure maximum coverage of all the LGAs in Nigeria. Nuclear medicine clinics are usually sited within an existing University Teaching and Research Hospitals (UTRHs) where the needed human resources can be readily obtained. There are 22 additional UTRHs which are potential sites for additional NMCs. However, constrained financial resources can limit how many of these UTRHs can serve as NMCs, hence the need to identify potential NMCs that will ensure adequate coverage of all LGAs in Nigeria at a given threshold distance. In all, only 11 of the UTRHs can be upgraded into NMCs to ensure that $84 \%$ of LGAs are within $200 \mathrm{~km}$ from the nearest clinics. The development of the NMCs can be prioritized based on the number of LGAs that will be served. The GIS-based MCLP algorithm was found suitable not only in the identification of the potential sites for the NMCs but also in allocating the required user population to the facility while ensuring adequate coverage of all the LGAs within the stipulated distance threshold. We propose that the influx of private investments in healthcare, especially oncology services, in Nigeria will lead to the next phase of growth for NM on the continent. It is hoped that the adoption of the optimal sites identified through the MCLP methods, will lead to more equitable NM services. Future consideration can enhance the percentage coverage of the LGAs and reduced the threshold distance specified. Further studies to evaluate the role of distance on the utilization of NM services are warranted.

Funding No fund was received for this study.

Data availability Data used can be made available without compromising any privacy issue.

Code availability We used ArcGIS 10.6 for the analysis of the optimal UTRHs.

\section{Decalarations}

Conflict of interest On behalf of all authors, the corresponding author states that there is no conflict of interest.

\section{References}

1. Parkin, D. M., Ferlay, J., Hamdi-Cherif, M., Sitas, F., Thomas, J.O., Wabinga, H., \& Whelan, S. L. (2003). Cancer in Africa
Epidemiology and Prevention, IARC (WHO) Scientific Publications no. 153, IARC Press, Lyon, France.

2. Omolara, K. A. (2011). Feasible cancer control strategies for Nigeria: mini-review. American Journal of Tropical Medicine \& Public Health, 1(1), 1-10

3. Smith, R. A., \& Haynes, S. (1992). Barriers to screening for breast cancer. Cancer, 69(S7), 1968-1978

4. Athas, W. F., Adams-Cameron, M., Hunt, W. C., Amir-Fazli, A., \& Key, C. R. (2000). Travel distance to radiation therapy and receipt of radiotherapy following breast-conserving surgery. Journal of the National cancer institute, 92(3), 269-271

5. Sariego, J. (2010). The impact of facility volume/size on breast cancer treatment and outcome. The American Surgeon, 76(12), 1333-1337

6. Ryan, S., Serrell, E. C., Karabon, P., Mills, G., Hansen, M., Hayn, M., Menon, M., Trinh, Q. D., Abdollah, F., \& Sammon, J. D. (2018). The association between mortality and distance to treatment facility in patients with muscle invasive bladder cancer. The Journal of Urology, 199(2), 424-429

7. Ronco, C., Bellomo, R., Kellum, J. A., \& Ricci, Z. (2017). Critical care nephrology e-book. Elsevier Health Sciences.

8. Ziessman, H. A., O'Malley, J. P., \& Thrall, J. H. (2013). Nuclear medicine: The requisites e-book. Elsevier Health Sciences.

9. Adedapo, K. S., Onimode, Y. A., Ejeh, J. E., \& Adepoju, A. O. (2013). Avoidable challenges of a nuclear medicine facility in a developing nation. Indian Journal of Nuclear Medicine: IJNM: The Official Journal of the Society of Nuclear Medicine, India, 28(4), 195

10. Ross, N. A., Rosenberg, M. W., \& Pross, D. C. (1994). Siting a women's health facility: A location-allocation study of breast cancer screening services in Eastern Ontario. Canadian Geographer/Le Géographe canadien, 38(2), 150-161

11. WHO. (2002). National Cancer Control Programmes; policies and managerial guidelines 2nd ed.

12. Disease Control Priorities Project (DCPP). (2007). Controlling cancer in developing countries; prevention and treatment strategies merit further study. www.dcp2.org.

13. Baade, P. D., Dasgupta, P., Aitken, J. F., \& Turrell, G. (2011). Distance to the closest radiotherapy facility and survival after a diagnosis of rectal cancer in Queensland. Medical Journal of Australia, 195(6), 350-354

14. Boscoe, F. P., Johnson, C. J., Henry, K. A., Goldberg, D. W., Shahabi, K., Elkin, E. B., Ballas, L. K., \& Cockburn, M. (2011). Geographic proximity to treatment for early stage breast cancer and likelihood of mastectomy. The Breast, 20(4), 324-328

15. Go, R. S., Bartley, A. C., Crowson, C. S., Shah, N. D., Habermann, E. B., Holton, S. J., \& Holmes, D. R., III. (2017). Association between treatment facility volume and mortality of patients with multiple myeloma. Journal of Clinical Oncology, 35(6), 598-604

16. Shukla, N., Wickramasuriya, R., Miller, A., \& Perez, P. (2015). An approach to plan and evaluate the location of radiotherapy services and its application in the New South Wales, Australia. Computer Methods and Programs in Biomedicine, 122(2), 245-256

17. Lazovich, D. A., White, E., Thomas, D. B., \& Moe, R. E. (1991). Underutilization of breast-conserving surgery and radiation therapy for women with stage I and II breast cancer. JAMA, 1991(266), 3433-3438

18. Faruque, F. S., Zhang, X., Nichols, E. N., Bradley, D. L., ReevesDarby, R., Reeves-Darby, V., \& Duhé, R. J. (2015). The impact of preventive screening resource distribution on geographic and population-based disparities in colorectal cancer in Mississippi. BMC Research Notes, 8(1), 423

19. Taiwo, O. J. (2020). Maximal Covering Location Problem (MCLP) for the identification of potential optimal COVID-19 
testing facility sites in Nigeria. African Geographical Review, $1-17$.

20. Nichols, E. N., Bradley, D. L., Zhang, X., Faruque, F., \& Duhé, R. J. (2014). The geographic distribution of mammography resources in Mississippi. Online Journal of Public Health Informatics, 5(3), 226

21. Owoaje, E. T., Amoran, O. E., Osemeikhain, O., \& Ohnoferi, O. E. (2005). Incidence of road traffic accidents and pattern of injury among commercial motorcyclists in a rural community in southwestern Nigeria. Journal of Community Medicine and Primary Health Care, 17(1), 7-12

22. Oyedepo, O. J., \& Makinde, O. (2010). Accident prediction models for Akure-Ondo carriageway, Ondo State Southwest Nigeria; using multiple linear regressions. African Research Review, 4(2).

23. Van den Wyngaert, T., Elvas, F., De Schepper, S., Kennedy, J. A., \& Israel, O. (2020). SPECT/CT: Standing on the shoulders of giants, it is time to reach for the sky! Journal of Nuclear Medicine, 61(9), 1284-1291

24. Cutler, C. S., Bailey, E. A., Kumar, V., Schwarz, S. W., Bom, H. H. S., Hatazawa, J., Paez, D., Orellana, P., Louw, L., Mut, F., \& Kato, H. (2020). Global issues of radiopharmaceutical access and availability: a nuclear medicine global initiative project. Journal of Nuclear Medicine, 62, 422-430

25. Dondi, M., Kashyap, R., Paez, D., Pascual, T., Zaknun, J., Mut Bastos, F., \& Pynda, Y. (2011). Trends in nuclear medicine in developing countries. Journal of Nuclear Medicine, 52(2), 16S

26. Orunmuyi, A. T., Lawal, I. O., Omofuma, O. O., Taiwo, O. J., \& Sathekge, M. M. (2020). Underutilisation of nuclear medicine scans at a regional hospital in Nigeria: need for implementation research. Ecancermedicalscience, 14, 1093

27. Dondi, M. (2013, May). Guest editorial: IAEA approach to meet nuclear medicine needs of the emerging world. In Seminars in Nuclear Medicine (Vol. 43, No. 3, pp. 159-160).

28. Dapel, Z. (2018). Will the Poor in Nigeria Escape Poverty in Their Lifetime? Center for Global Development Working Paper, (483).
29. Ye, B. S., Seo, S. W., Kim, C. H., Jeon, S., Kim, G. H., Noh, Y., Cho, H., Yoon, C. W., Kim, H. J., Jang, E. Y., \& Lee, J. (2014). Hippocampal and cortical atrophy in amyloid-negative mild cognitive impairments: Comparison with amyloid-positive mild cognitive impairment. Neurobiology of ageing, 35(2), 291-300

30. Hensher, M., Price, M., \& Adomakoh, S., et al. (2006). Referral hospitals in disease control priorities in developing countries. In D. T. Jamison, J. G. Bregman, \& A. R. Measham (Eds.), Disease control priorities in developing countries. (2nd ed.). The International Bank for Reconstruction and Development/The World Bank.

31. Goksel, F., Peksoy, I., Koc, O., Gultekin, M., Ozgul, N., \& Sencan, I. (2012). Planning of nuclear medicine in Turkey: Current status and future perspectives. Asian Pacific Journal of Cancer Prevention, 13(5), 1989-1994

32. Polo, G., Acosta, C. M., Ferreira, F., \& Dias, R. A. (2015). Location-allocation and accessibility models for improving the spatial planning of public health services. PLOS ONE, 10(3), e0119190

33. Rahman, S. U., \& Smith, D. K. (2000). Use of location-allocation models in health service development planning in developing nations. European Journal of Operational Research, 123, 437-452

34. Turner, M., Fielding, S., Ong, Y., Dibben, C., Feng, Z., Brewster, D. H., Black, C., Lee, A., \& Murchie, P. (2017). A cancer geography paradox? Poorer cancer outcomes with longer travelling times to healthcare facilities despite prompter diagnosis and treatment: a data-linkage study. British Journal of Cancer, $117(3), 439-449$

35. http://www.mdenigeria.org/Internship\%20Training\%20Centres. htm.

Publisher's Note Springer Nature remains neutral with regard to jurisdictional claims in published maps and institutional affiliations. 